MOLECULAR ASPECTS OF ANTI-CANCER DRUG ACTION 


\section{TOPICS IN MOLECULAR AND STRUCTURAL BIOLOGY}

General Editors:

Watson Fuller

(University of Keele)

and

Stephen Neidle

(King's College

University of London)

Previous published books in this series:

Topics in Nucleic Acid Structure Part 1 Edited by Stephen Neidle Topics in Nucleic Acid Structure Part 2 Edited by Stephen Neidle 


\title{
MOLECULAR ASPECTS OF ANTI-CANCER DRUG ACTION
}

Edited by

STEPHEN NEIDLE

Cancer Research Campaign

Biomolecular Structure Research Group

King's College University of London

$$
\text { and }
$$

\section{MICHAEL J. WARING}

\author{
Department of Pharmacology
}

University of Cambridge Medical School

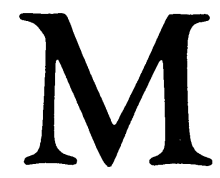


(C) The Contributors 1983

Softcover reprint of the hardcover 1st edition 1983 978-0-333-31556-9

All rights reserved. No part of this publication may be reproduced or transmitted in any form or by any means, without permission

First published 1983 by

The Scientific and Medical Division

THE MACMILLAN PRESS LIMITED

London and Basingstoke

Companies and representatives

throughout the world

ISBN 978-1-349-06012-2

ISBN 978-1-349-06010-8 (eBook)

DOI 10.1007/978-1-349-06010-8

Typeset by

RDL Artset Ltd, Sutton, Surrey 


\section{Contents}

The Contributors vii

Preface $\quad$ ix

1 Antitumour Acridines

William A. Denny, Bruce C. Baguley, Bruce F. Cain and

Michael J. Waring 1

2 The Interactions of Daunomycin and Adriamycin with Nucleic Acids

S. Neidle and M. R. Sanderson 35

3 New Natural, Semisynthetic and Synthetic Anthracycline Drugs

J. R. Brown 57

4 Mechanisms of Selective Cytotoxicity of Adriamycin, Daunomycin and Related Anthracyclines

Herbert S. Schwartz

5 Molecular Aspects of the Interaction between Quinoxaline Antibiotics and Nucleic Acids

Michael J. Waring and Keith R. Fox

6 Bleomycin

Lawrence F. Povirk

7 Action of Platinum Antitumour Drugs

J. J. Roberts and M. P. Pera, Jr.

8 Molecular Structure and Antitumour Acivity of Alkylating Agents

Derry E. V. Wilman and Thomas A. Connors

9 The Chemistry of DNA Damage by Antitumour Drugs

J. William Lown

10 Biological Aspects of DNA Damage by Crosslinking Agents

Kurt W. Kohn

11 Inhibitors of Dihydrofolate Reductase

B. Roth, E. Bliss and C. R. Beddell 


\section{The Contributors}

B. C. Baguley

Cancer Research Laboratory

University of Auckland

School of Medicine

Auckland

New Zealand

C. R. Beddell

Wellcome Research Laboratories

Langley Court

Beckenham

Kent BR3 3BS

UK

E. Bliss

University of Oxford

Nuffield Department of Pathology

John Radcliffe Hospital

Oxford OX3 9DU

UK

J. R. Brown

Department of Pharmaceutical Chemistry Faculty of Pharmaceutical Sciences

Sunderland Polytechnic

Sunderland SR 1 3SD

UK

B. F. Cain (the late)

Cancer Research Laboratory

University of Auckland

School of Medicine

Auckland

New Zealand

T. A. Connors

Medical Research Council Toxicology

Unit

Woodmansterne Road

Carshalton

Surrey SM5 6JB

UK

W. A. Denny

Cancer Research Laboratory

University of Auckland

School of Medicine

Auckland

New Zealand
K. R. Fox

University of Cambridge

Department of Pharmacology

Medical School

Hills Road

Cambridge CB2 2QD

UK

K. W. Kohn

Laboratory of Molecular Pharmacology

Division of Cancer Treatment

National Cancer Institute

National Institute of Health

Bethesda

Maryland 20205

USA

J. W. Lown

Department of Chemistry

University of Alberta

Edmonton T6G 2G2

Alberta

Canada

S. Neidle

Cancer Research Campaign

Biomolecular Structure Research Group

Department of Biophysics

King's College

26-29 Drury Lane

London WC2B 5RL

UK

M. P. Pera, Jr.

Institute of Cancer Research

Royal Cancer Hospital

Pollards Wood Research Station

Nightingales Lane

Chalfont St. Giles

Bucks HP8 4SP

UK

L. F. Povirk

Department of Pharmacology

Harvard Medical School

Boston

Massachusetts 02115

USA 


\section{J. J. Roberts}

Institute of Cancer Research

Royal Cancer Hospital

Pollards Wood Research Station

Nightingales Lane

Chalfont St. Giles

Bucks HP8 4SP

UK

B. Roth

Burroughs Wellcome Co.

3030 Cornwallis Road

Research Triangle Park

North Carolina 27709

USA

M. R. Sanderson

Gorlaeus Laboratories

The State University of Leiden

2300 RA Leiden

The Netherlands

H. S. Schwartz

Department of Experimental Therapeutics and Grace Cancer Drug Center Roswell Park Memorial Institute New York State Department of Health 665 Elm Street

Buffalo

New York 14263

USA
M. J. Waring

University of Cambridge

Department of Pharmacology

Medical School

Hills Road

Cambridge CB2 2QD

UK

D. E. V. Wilman

Department of Biochemical Pharmacology

Institute of Cancer Research

Royal Cancer Hospital

Clifton Avenue

Belmont

Sutton

Surrey SM2 5PX

UK 


\section{Preface}

The idea that understanding the molecular bases of drug action will lead to major advances in medical practice is not new. It has been hallowed by the award of prestigious prizes. It has become enshrined in the thinking of a generation of scientists and physicians. Few people are brave (or foolhardy) enough to doubt the enormous potential of fundamental studies as a guide to drug design. This book represents an attempt to summarise certain areas of endeavour which provide a timely assessment of progress: it is unashamedly wedded to the concept that molecular and structural studies will point the way ahead.

A glance at the list of contents will reveal that it is in no sense comprehensive. On the contrary, in selecting chapter titles and authors we were guided first and foremost by considerations of topicality, particularly as regards molecular interpretations. Even so, it is easy to point to yawning gaps in our coverage of the subject and we hope no-one will feel offended if there is no mention of his or her favourite drug or modality of cancer treatment. With much regret we have tended to avoid discussion of clinical applications/applicability though we are conscious of the vitally important goal of transporting the insights and innovations of the laboratory into the clinic. Perhaps that aspect alone is worthy to form the subject of another volume.

There is an obvious preoccupation with matters concerning drug-nucleic acid interactions, if only because they are so amenable to investigation at the molecular level. But this is not intended to imply that drugs have a single sitespecific mode of action or that DNA is the only important receptor for anticancer drugs. Indeed, we have deliberately encouraged several authors to adopt the role of "devil's advocate" and to examine critically the possibility of significant effects mediated by antitumour drugs at levels other than that of nucleic acids. It is clear that for many useful compounds the very concept of a primary site of action must be held open to question.

It may appear that the treatment of antimetabolites is particularly deficient, granted their prominent place in various cancer treatment regimes. This is chiefly due to our insistence on limiting attention to topics where a substantial body of information at the molecular level is available for the receptor - realistically a crystal structure from which precise molecular structural data can be derived. Such information is now available for dihydrofolate reductase, which therefore represents the outstanding example of a well-characterised antimetabolite receptor. 
Until two or three years ago it was natural to regard the double-helical tenfold B-form as the final word on DNA structure, and therefore the best-defined receptor for anticancer drug action. However, recent developments outlined in the first two volumes of this series reveal that we must discard the notion that DNA is a monotonously repeating biopolymer. Sequence-dependent variation of the local conformation of DNA is now a serious concept which presents an alluring challenge to those who would seek molecular interpretations of drug action.

Inevitably considerations of space have forced us to neglect a number of interesting areas where molecular insights are currently being applied to develop new drugs with promising clinical potential. We can only hope that the principles which emerge from the existing chapters will prove to be of sufficient generality to serve as pointers to developments in related fields.

Lastly, we hope the book may prove useful to physicians and others whose principal concern is with the use of drugs in the clinic to treat cancer, as well as to the more obvious audience of laboratory research workers. Our underlying belief remains that fundamental studies cannot be neglected in assessing future priorities: indeed we are prepared to argue that they represent the cornerstone of the subject, and this attitude (perhaps better described as an article of faith) is implicit in the message of several contributions. In this claim we make no boast for originality, only a driving concern to make best use of molecular and structural biology in the service of medicine.

Stephen Neidle

Michael Waring 